\title{
Medical Management of the Surgical Patient: A Textbook of Perioperative Medicine - Fourth Edition
}

\author{
Michael F. Lubin (Editor-in-Chief). Cambridge University Press, 2010. \\ ISBN 978-0-521-82800-0 hardback; 978-0-521-18011-5 paperback
}

Neal Badner, MD

Received: 10 May 2011/Accepted: 18 May 2011/Published online: 28 May 2011

(C) Canadian Anesthesiologists' Society 2011

This textbook is the newly released paperback version (2010) of the fourth edition previously published in hard cover in 2006. It is a multi-edited (four), multi-authored (120, in fact) collaboration of mostly internists and surgeons. The goal of the text is to "provide an authoritative account of all aspects of perioperative care for all surgical patients". This is not a small undertaking. In essence, the text is designed as a reference for physicians dealing with the medical management of surgical patients.

The textbook is divided into two sections. The first section, "Medical Management", includes 41 chapters that deal with most medical system co-morbidities as well as psychiatric and obstetric pathophysiology. These chapters are well written and relatively detailed with extensive references. This section is comparable with texts such as Stoelting's Anesthesia and Co-Existing Disease, $5^{\text {th }}$ Edition (2008) published by Saunders. The second section, "Surgical Procedures and Complications", includes ten subsections covering most types of surgery (e.g., vascular, thoracic, orthopedic, etc.) and 94 chapters dealing with virtually every type of surgical procedure. This text makes an excellent reference for physicians who have little exposure to the operating room, as the two sections combined provide an authoritative reference for all medical concerns involving a surgical patient.

There are, however, two main limitations to this book. First, although it is a new paperback edition, the text entails
813 (8.5 x 11 in) pages and, essentially, appears to be a reprinting of the 2006 edition without the hard cover. Ironically, most of the impact of this revision is on the chapter, "Anesthesia management of the surgical patient", which is rather brief and suffers from referencing the 2002 American College of Cardiology/American Heart Association (ACC/AHA) guidelines on the perioperative management of patients undergoing non-cardiac surgery. The ACC/AHA guidelines have been revised twice prior to this new paperback edition. Second, the writing style in the second section of the text differs significantly from the writing style in the first section. The chapters are briefer, the references are fewer, and the references are listed in a format different from that in the first section. The chapter, "Skin grafting for burns", is only two pages with four references, while the chapter, "Postoperative pulmonary complications", is 18 pages with 120 references. It appears as though two different books were simply pasted together.

Despite the above limitations, I would recommend this book for internists or primary care physicians who do not have a detailed understanding of surgery yet look after the perioperative management of surgical patients. I would also recommend this book for use as a reference text in libraries of large anesthesiology departments with active consultation services.

N. Badner, MD $(\bowtie)$

University of Western Ontario, London, ON, Canada

e-mail: neal.badner@1hsc.on.ca 